\title{
FREQUENCY OF BCG VACCINATION IN CHILDREN WITH TUBERCULOUS MENINGITIS AT LIAQUAT UNIVERSITY HOSPITAL HYDERABAD.
}

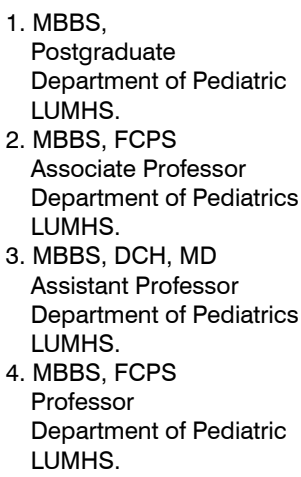

Correspondence Address:

Dr. Farzana Shaikh

Flat No. 215/216. Block C,

VIP Apartment. Phase-I

Qasiamabad Hyderabad.

farzana.dr.shaikh@gmail.com

Article received on:

12/02/2019

Accepted for publication:

25/06/2019

Received after proof reading:

30/09/2019

\begin{abstract}
Shamaeel', Farzana Shaikh ${ }^{2}$, Ghulam Shabbir Laghari ${ }^{3}$, Yasmeen Memon ${ }^{4}$
ABSTRACT... Objectives: To determine the frequency of BCG vaccination in children with tuberculous meningitis of age 01 to 12 years at Liaquat University Hospital Hyderabad. Study Design: Cross sectional descriptive study. Setting: Department of Pediatrics, Liaquat University Hospital, Jamshoro / Hyderabad. Period: Six months from 20-08-2016 to 20-022017. Material and Methods: A total of 189 children with history of fever (axillary temperature $>37.2^{\circ} \mathrm{C}$ ) for $\geq 14$ days duration with presentation, CT scan and CSF findings consistent with tuberculous meningitis were selected in this study. The data was collected on pre-structured proforma (attached). Results: There were $86(45.5 \%)$ male and 103(54.5\%) female. Frequency of BCG vaccination in children with tuberculosis meningitis was found in $130(68.78 \%)$ cases. Conclusion: Our results show effectiveness of BCG vaccine in preventing TBM. Regardless of the protective efficacy of BCG in preventing pulmonary tuberculosis, in areas in which tuberculosis affects a significant percentage of the population, continued use of BCG may be warranted to prevent tuberculous meningitis.
\end{abstract}

Key words: Tuberculous Meningitis, BCG Vaccination, Pulmonary Tuberculosis.

Article Citation: Shameel, Shaikh F, Laghari GS, Memon Y. Frequency of BCG vaccination in children with tuberculous meningitis of age 01 to 12 years at Liaquat University Hospital Hyderabad. Professional Med J 2019; 26(10):16651671. DOI: 10.29309/TPMJ/2019.26.10.3280

\section{INTRODUCTION}

Tuberculosis keeps on being a noteworthy general medical issue internationally while tuberculous meningitis (TBM) is the most perilous type of tuberculosis specifically observed in children. ${ }^{1,2}$ TBM remains an essential reason for hospitalization, demise, and changeless neurological incapacity in kids in Pakistan..$^{3,4}$ Over the years there has been no critical decrease in the rate of this destructive ailment, notwithstanding the cases of high immunization inclusion with the Bacillus-Calmette-Guerin (BCG) antibody. ${ }^{5}$

Despite the fact that the BCG antibody has been utilized for more than 80 years, there remains a sorry excuse for uncertainty in regards to its incentive in insurance against tuberculosis. ${ }^{6}$ Although the defensive adequacy of BCG immunization in grown-up types of the illness is dubious, it is held to be helpful in keeping the spread of and enhancing result of tubercular infection. ${ }^{7}$ Vaccinated kids prepare their cell invulnerable reactions all the more viably when presented to regular tuberculous disease in spite of the fact that encountering haematogenous intricacies, for example, miliary tuberculosis and TBM. ${ }^{8}$ However this insurance is just relative and might be defeated in nearness of an overwhelming contaminating portion from a family contact, within the sight of extreme hunger and as a result of winding down insusceptibility numerous years after vaccination. ${ }^{9}$ There are few reports in the writing that depict particular clinical range of TBM in BCG immunized children ${ }^{10,11}$, while the revealed commonness for BCG immunization in youngsters with tuberculous meningitis was $77 \%$ in the investigation by Thilothammal $\mathrm{N}$, et al. ${ }^{12}$

Therefore, it is important to recognize the frequency of BCG vaccination in children with TBM of 1 to 12 years of age, so that early protective parameters can be achieved. The data regarding the BCG vaccination in children with TBM is scarce in our population while the study 
was supportive for primary care pediatrician and health care providers for the evaluation of BCG vaccination in children presented with tuberculous meningitis because early screening was helpful to take appropriate measures whereas the decision for management plan can be taken according to the results of the study.

\section{MATERIAL AND METHODS}

The Cross sectional descriptive study was conducted in the department of Pediatrics, Liaquat University Hospital, Jamshoro / Hyderabad (20-08-2016 to 20-02-2017). Total 189 children with tuberculous meningitis was taken by non-probability consecutive sampling. The inclusion criteria were the children of 01 to 12 years of age, of either gender have history of fever (axillary temperature $>37.2^{\circ} \mathrm{C}$ ) for $\geq 14$ days duration with presentation, CT scan and CSF findings consistent with tuberculous meningitis (mentioned in operational definition).

\section{(I) TUBERCULOUS MENINGITIS}

(a) Clinical presentation with fever (axillary temperature $\geq 37.2^{\circ} \mathrm{C}$ ) for 14 days

(b) Cranial / Brain CT scan

(c) Cerebrospinal fluid (CSF) shows raised protein ( $>400 \mathrm{mg} / \mathrm{dl}$ ), decrease glucose $(<40 \mathrm{mg} / \mathrm{dl}$ ) and pleocytosis with predominant lymphocytes ( $>10$ cells $/ \mathrm{mm}^{3}$ ).

The tuberculous meningitis was labeled when all of the above given parameters $(\mathrm{a}-\mathrm{c})$ are present.

\section{(II) BCG VACCINATION}

Was observed through gross physical examination (sign) by the presence of a scar with raised center on the left shoulder / arm

\section{Exclusion Criteria}

The children with history of congenital anomalies of CNS (encephalocele, microcephaly), brain tumors, cerebral malaria and abscess, the children already on anti-tuberculous therapy and the bacterial and viral meningitis.

The above mentioned disorders was evaluated by the specific history and relevant clinical examinations so that the effect modifiers can be controlled. Moreover, by the existence of previous medical record, hospitalization, laboratory investigations evidences and diagnosed slips given by consultant pediatrician mentioning such disorders as a diagnosis.

All children presenting in pediatric department of Liaquat University Hospital Hyderabad / Jamshoro with fulfillment of the inclusion criteria was recruited and enrolled in the study. The tuberculosis meningitis children were assessed for BCG vaccination scar according to the criteria and parameter mentioned in the operational definition. The senior consultant pediatrician of the ward was confirmed the scar while the written consent was taken from parents / guardians to participate in the study. The data was collected on pre-structured proforma (attached). Regarding financial compensation, all the expenditures of the study was bear by researcher and all the clinical maneuvers (history taking and clinical examinations) was performed by me under the supervision of senior consultant pediatrician (have $\geq 05$ years clinical experience) in the pediatric department.

The data of all patients was analyzed in SPSS version 17.00. The frequency and percentage (\%) was calculated for BCG vaccination in children with TBM and also for gender distribution. The qualitative variables are gender and BCG vaccinations while the mean \pm standard deviation (SD) was calculated for numerical / quantitative variables (age, BMl and duration).

The stratification was done for age, gender, BMl (measure in $\mathrm{kg} / \mathrm{m}^{2}$ ), rural, urban, acute malnutrition and duration of disease to see the effect on outcome and the $p$-value $\leq 0.05$ was considered as statistically significant.

\section{RESULTS}

A total of 189 children with history of fever (axillary temperature $>37.2^{\circ} \mathrm{C}$ ) for $\geq 14$ days duration with presentation, CT scan and CSF findings consistent with tuberculous meningitis were selected in this study. Most of the children were 1 to 5 years of age as shown in Figure-1. There were 86(45.5\%) male and 103(54.5\%) female (Figure-2). Out of 189 children, $53.97 \%$ were belonged to urban 
and $46.03 \%$ belong to rural as shown in Figure-3. An acute malnutrition observed in $77(40.74 \%)$ as shown in Figure-4.

Frequency of BCG vaccination in children with tuberculosis meningitis was found in 130(68.78\%) cases as presented in Figure-5. Stratification analysis was performed and observed that there was no significant difference in frequency of $B C G$ vaccination between age groups as shown in Table-I\&II. Similarly this difference was not observed between male and female and urban and rural as shown in Table-III and IV respectively. Frequency of $B C G$ vaccination was significant with $\mathrm{BMI}$, duration of disease and acute malnutrition as shown in Table-V to VII.

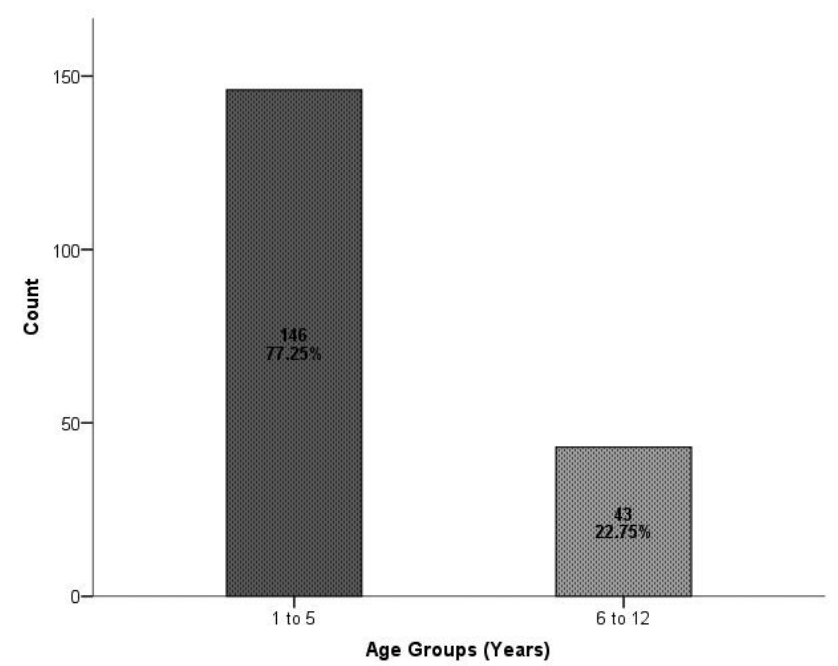

Figure-1. Age distribution of the patients $n=189$

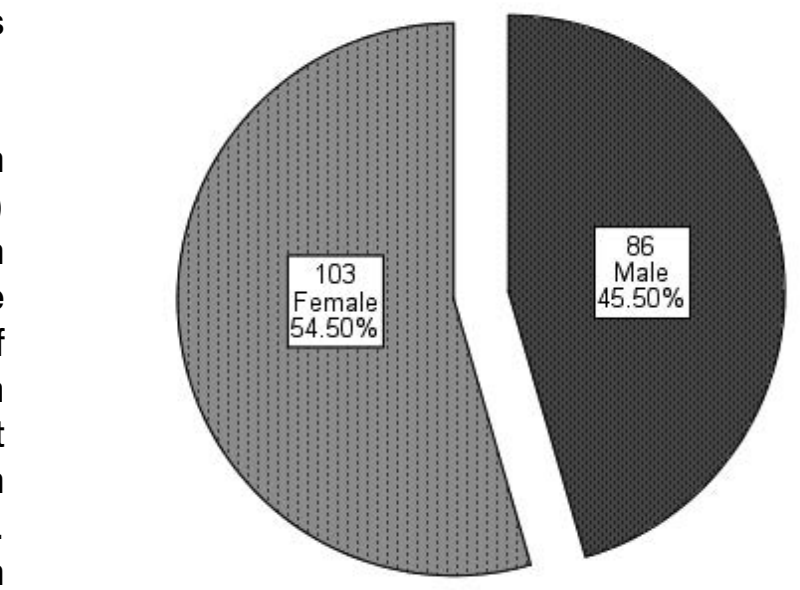

Figure-2. Gender distribution $n=189$

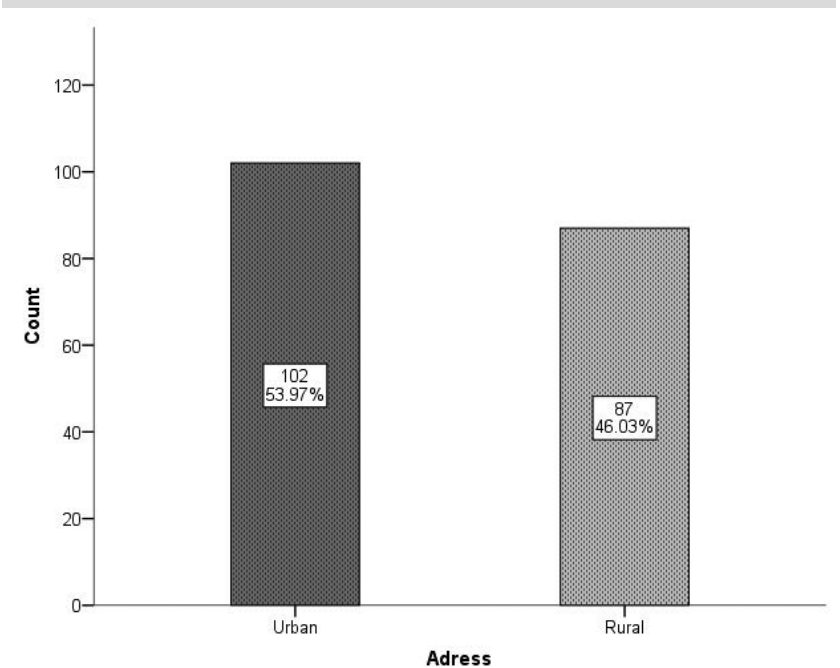

Figure-3. Rural distribution $n=189$

\begin{tabular}{|l|c|c|c|c|}
\hline \multicolumn{2}{|c|}{ Statistics } & Age (Years) & BMI (kg/m²) & Duration of Disease (Days) \\
\hline Mean & & 4.77 & 20.06 & 5.84 \\
\hline \multirow{2}{*}{ Std. Deviation } & 2.55 & 3.44 & 1.53 \\
\hline \multirow{2}{*}{\begin{tabular}{l} 
95\% Confidence Interval for Mean \\
\cline { 2 - 5 }
\end{tabular}} & Lower Bound & 4.41 & 19.57 & 5.62 \\
\cline { 2 - 5 } Median & Upper Bound & 5.14 & 20.56 & 6.06 \\
\hline Interquartile Range & 4.20 & 20.76 & 6.00 \\
\hline
\end{tabular}

Table-I. Demographic characteristics of patients $n=189$

\begin{tabular}{|c|c|c|c|c|}
\hline Age Groups (Years) & \multicolumn{2}{|c|}{ BCG Vaccination } & Total & P-Value \\
\hline 1 to 5 & 104(71.2\%) & $42(28.8 \%)$ & 146 & \multirow{2}{*}{0.180} \\
\hline 6 to 12 & $26(60.5 \%)$ & $17(39.5 \%)$ & 43 & \\
\hline
\end{tabular}




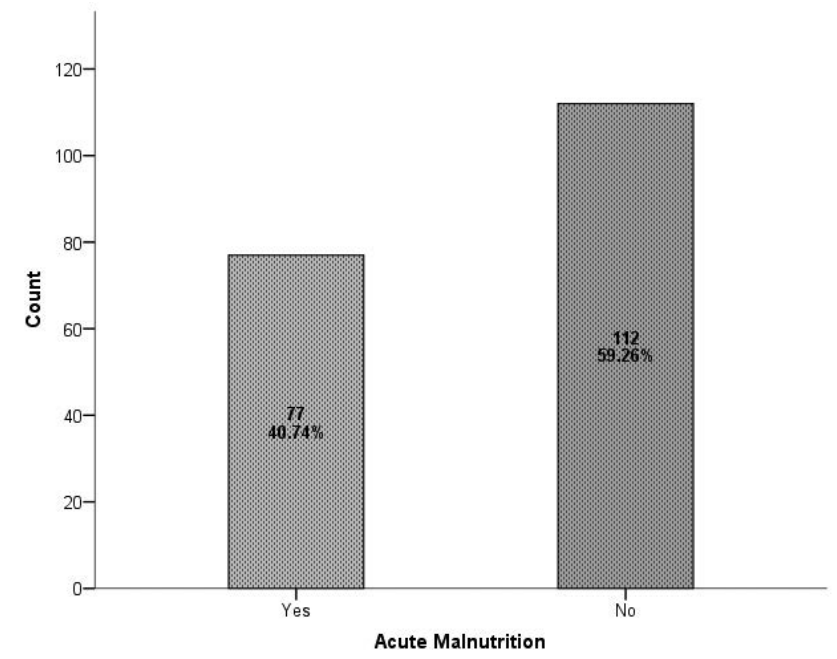

Figure-4. Acute malnutrition $n=189$

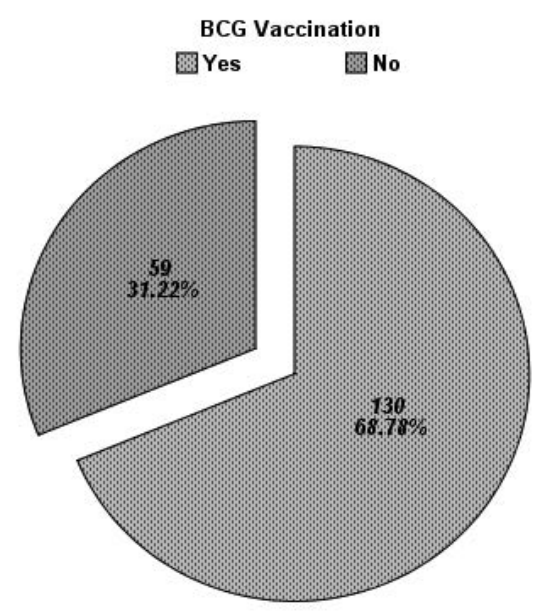

Figure-5. Frequency of BCG vaccination in children with tuberculous meningitis $n=189$

\begin{tabular}{|l|c|c|c|c|}
\hline \multirow{2}{*}{ Gender } & \multicolumn{2}{c|}{ BCG Vaccination } & \multicolumn{2}{c|}{ Total } \\
\cline { 1 - 4 } & Yes & No & 86 & \\
\hline Male & $60(69.8 \%)$ & $26(30.2 \%)$ & 103 & 0.790 \\
\hline
\end{tabular}

Table-III. Frequency of BCG vaccination in children with tuberculous meningitis by gender $n=189$

Chi-Square $=0.071$

\begin{tabular}{|l|c|c|c|c|}
\hline \multirow{2}{*}{ Residence } & \multicolumn{2}{|c|}{ BCG Vaccination } & Total & P-Value \\
\cline { 2 - 5 } & Yes & No & 102 & 0.190 \\
\hline Urban & $66(64.7 \%)$ & $36(35.3 \%)$ & 87 & 0.190 \\
\hline Rural & $64(73.6 \%)$ & $23(26.4 \%)$ & \\
\hline
\end{tabular}

Table-IV. Frequency of BCG vaccination in children with tuberculous meningitis by residence $n=189$ Chi-Square $=1.716$

\begin{tabular}{|l|c|c|c|c|}
\hline \multirow{2}{*}{ BMI } & \multicolumn{2}{|c|}{ BCG Vaccination } & Total & P-Value \\
\hline$<18.5$ & & Yes & No & 79 \\
\hline$\geq 18.5$ & & $71(89.9 \%)$ & $8(10.1 \%)$ & 0.0005 \\
\hline
\end{tabular}

Table-V. Frequency of BCG vaccination in children with tuberculous meningitis by $B M I n=189$ Chi-Square $=28.18$

\begin{tabular}{|c|c|c|c|c|}
\hline \multirow{2}{*}{ Duration of Disease } & \multicolumn{2}{|c|}{ BCG Vaccination } & \multirow{2}{*}{ Total } & \multirow{2}{*}{ P-Value } \\
\hline & Yes & No & & \\
\hline$\leq 6$ days & $104(73.8 \%)$ & $37(26.2 \%)$ & 141 & \multirow{2}{*}{0.011} \\
\hline$>6$ days & $26(54.2 \%)$ & $22(45.8 \%)$ & 48 & \\
\hline
\end{tabular}

Table-VI. Frequency of BCG vaccination in children with tuberculous meningitis by duration of disease $n=189$ Chi-Square $=6.402$

\begin{tabular}{|l|c|c|c|c|}
\hline \multirow{2}{*}{ Acute Malnutrition } & \multicolumn{2}{c|}{ BCG Vaccination } & Total & P-Value \\
\cline { 1 - 4 } & Yes & No & 77 & 0.0005 \\
\hline Yes & $69(89.6 \%)$ & $8(10.4 \%)$ & 112 & $0.005)$ \\
\hline No & $51(54.5 \%)$ & $51(45.5 \%)$ & $17 \%$ \\
\hline
\end{tabular}

Table-VII. Frequency of BCG vaccination in children with tuberculous meningitis by acute malnutrition $n=189$ Chi-Square $=26.25$ 


\section{DISCUSSION}

Tuberculosis keeps on being an across the board sickness particularly in creating nations. Tuberculous meningitis, a genuine inconvenience of this disease, happens in $7-12 \%$ of patients with tuberculosis and it is progressively regular in children. In youngsters, even with treatment, the mortality of tuberculous meningitis is $27 \%$ and changeless inability is assessed to be as high as $39 \% .{ }^{13}$ Tuberculosis (T.B) is in charge of real weight on wellbeing and financial matters low pay areas in which Pakistan is additionally included. Pakistan positions 6th on the planet having 1.5 million TB patients, with 250,000 new cases each year. Globally the malady is in charge of 26 percent avoidable passings. The rate of TB is 181/100000 and out of which half are AFB positive cases1. The precise figures of youth TB in Pakistan is obscure. Bacillus Calmette- Guérin (BCG) antibody is an immunization basically utilized against tuberculosis. ${ }^{14}$ In nations where tuberculosis is normal, one portion is prescribed in sound infants as near the season of birth as possible. Rates of security against tuberculosis contamination fluctuate generally and assurance endures somewhere in the range of ten and twenty years. Among youngsters it keeps about $20 \%$ from getting tainted and among the individuals who do get contaminated it shields half from creating disease ${ }^{15}$ In this study to determine the frequency of BCG vaccination in children with tuberculous meningitis of age 01 to 12 years, A total of 189 children with history of fever (axillary temperature $>37.2^{\circ} \mathrm{C}$ ) for $\geq 14$ days duration with presentation, CT scan and CSF findings consistent with tuberculous meningitis were selected. Children aged 6 months to 5 years are among the age groups most frequently suffering from TBM. ${ }^{8,16}$ In our study out of 189 children, $77.2 \%$ were from 1 to 5 years of age reflecting most vulnerable age. So it is clear that children under the age of 5 years were vulnerable and these should be prevented from tuberculous infection. Our observation is supported by other studies. N Thilothammal et al in their prospective study reported the age of the 107 patients ranged from 6 months to 12 years. The number of children under 5 years was $69 \% .{ }^{17}$ Ailing health and tuberculosis are the two issues of extensive extent in the greater part of the immature areas of the world. Lack of healthy sustenance is a noteworthy wellbeing danger and mother of all issues in pediatric diseases. ${ }^{18,19}$ It improves the dismalness as well as builds the death rate in kids. The term utilization has been for all intents and purposes synonymous with tuberculosis since the commencement ${ }^{20}$ and the connection among tuberculosis and ailing health has for quite some time been perceived; hunger may incline individuals to the improvement of clinical sickness and tuberculosis can add to malnutrition. ${ }^{21}$ In our examination intense lack of healthy sustenance youngster was seen in $77(40.74 \%)$.

Inoculation during childbirth with BCG is generally connected as a feature of the Expanded Program on Immunization of the WHO. ${ }^{22}$ Appraisals of its adequacy differ ${ }^{23}$, attributable to an assortment of putative components. ${ }^{24,25}$ The degree to which BCG immunization manages security against TBM is still discussed. As an ever increasing number of youngsters are being inoculated with $B C G$, the clinical range of the sickness (TBM) might change. A meta-examination of the distributed preliminaries on the viability of BCG inoculation proposed a defensive impact of $64 \%$ against TBM. ${ }^{26}$ This figure is higher than that recommended for aspiratory TB (half), however may just reflect progressively precise case ascertainment of TBM given the all inclusive prerequisite for admission to clinic. Generally speaking, these and different investigations bolster the view that BCG immunization is defensive against TBM.

In our investigation Frequency of BCG immunization in kids with tuberculosis meningitis was found in $68.78 \%$ cases, appearing of BCG antibody in counteracting TBM. The outcomes from studies attempted to discover the adequacy of BCG in anticipating tuberculous meningitis have been empowering and the defensive viability has extended from $52-84 \% .^{27,28,29}$ It is conceivable that BCG can forestall tuberculous meningitis by averting scattering of the tubercle bacillus inside the body regardless of whether passage isn't prevented..$^{30}$ In an investigation of 80 cases somewhere in the range of 1973 and 1975, Udani 
et al saw that the "cognizant" sort of TBM was multiple times everyday citizen in inoculated children. ${ }^{31}$ They additionally discovered that confined types of TBM happened all the more ordinarily in BCG immunized kids, while "great" TBM was considered twice to be regularly in the unvaccinated youngsters examined. Truly, Western nations that utilized BCG as a component of their TB control methodology did not encounter any more noteworthy decreases in the frequency or death rates from TB than nations that did not utilize BCG, for example, the Netherlands. In perspective of this, the estimation of BCG inoculation in controlling the transmission of Mycobacterium tuberculosis has been believed to be constrained. In any case, BCG is as yet viewed as helpful in lessening the frequency of tuberculous meningitis in youngsters.

\section{CONCLUSION}

Our outcomes show viability of BCG antibody in avoiding TBM. Notwithstanding the defensive adequacy of BCG in forestalling aspiratory tuberculosis, in zones in which tuberculosis influences a critical level of the populace, proceeded with utilization of BCG might be justified to counteract tuberculous meningitis. A noteworthy number of youngsters in our examination were discovered malnourished and as the connection among tuberculosis and lack of healthy sustenance has for quite some time been remembered, we suggest that in the TB destruction program the issue of Protein Calorie Malnutrition, particularly in youthful kids younger than 5 years, ought to likewise be managed. Each Health office should concentrate on giving BCG antibody during childbirth. The virus chain of $B C G$ antibody ought to be required which results into the viability of the BCG immunization and it restraints the recurrence of TBM.

\section{Acknowledgement}

We acknowledge Mr. Farooq Ahmed Mangnejo S/o Imam Bux for Bio-statistical help and other technical input.

Copyright@ 25 June, 2019.

\section{REFERENCES}

1. Schoeman JF, Donald PR. Tuberculous meningitis. Handb Clin Neurol. 2013; 112:1135-8.

2. Chin JH. Diagnostic and therapeutic challenges. Neurol Clin Pract. 2014; 4(3):199-205.

3. Hannan A, Hafeez A, Chaudary S, Rashid M. Rapid confirmation of tuberculous meningitis in children by liquid culture media. J Ayub Med Coll Abbottabad. 2010; 22(4):171-5.

4. Tariq S, Rauf A, Malik S, Rashid A. Presentations of tuberculosis in northern Pakistan. J Ayub Med Coll Abbottabad. 2011; 23(1):40-2.

5. Luca S, Mihaescu T. History of BCG Vaccine. Maedica (Buchar). 2013; 8(1):53-8.

6. Pereira SM, Barreto ML, Pilger D, Cruz AA, Sant'Anna C, Hijjar MA, et al. Effectiveness and cost-effectiveness of first BCG vaccination against tuberculosis in school-age children without previous tuberculin test (BCG-REVAC trial): A cluster-randomised trial. Lancet Infect Dis. 2012; 12(4):300-6.

7. Mangtani P, Abubakar I, Ariti C, Beynon R, Pimpin L, Fine $P E$, et al. Protection by $B C G$ vaccine against tuberculosis: A systematic review of randomized controlled trials. Clin Infect Dis. 2014; 58(4):470-80.

8. Principi N, Esposito S. Diagnosis and therapy of tuberculous meningitis in children. Tuberculosis (Edinb). 2012; 92(5):377-83.

9. Chow EJ, Toll E, Montague BT, Alexander-Scott N, Van Scoyoc $\mathrm{E}$. Tuberculous meningitis in child born in the US to immigrants from a tuberculosis-endemic country. R I Med J. 2014; 98(1):22-5.

10. Kumar P, Kumar R, Srivastava KL, Kumar M. Protective role of $B C G$ vaccination against tuberculous meningitis in Indian children: A reappraisal. Natl Med J India. 2005; 18(1):7-11.

11. Bhandari B, Mandowara SL. A study of tuberculosis in BCG vaccinated children. Indian Pediatr. 1982; 19:865-8.

12. Thilothammal N, Krishnamurthy PV, Runyan DK, Banu K. Does BCG vaccine prevent tuberculousmeningitis? Arch Dis Child. 1996; 74(2):144-7.

13. Padma R, Duraipandian $M$, Nagarajan $M$, Prabhakar R, Ramakrishnan CV, Tripathy SP. Three chemotherapy studies of tuberculosis meningitis in children. Tubercle. 1986; 67:17-29. 
14. "BCG Vaccine: WHO position paper" (PDF). Weekly Epidemiological Record. 2004; 4(79):25-40.

15. Roy A, Eisenhut M, Harris RJ, Rodrigues LC. "Effect of BCG vaccination against Mycobacterium tuberculosis infection in children: Systematic review and meta-analysis". BMJ (Clinical research ed.). 2014; 349:94643.

16. Ducomble T, TolksdorfK, Karagiannis I, Hauer B, Brodhun B, Haas W, et al. The burden of extra pulmonary and meningitis tuberculosis: An investigation of national surveillance data, Germany, 2002 to 2009. Euro Surveill. 2013; 18(12):20436.

17. Thilothammal N, Krishnamurthy PV. Does BCG vaccine prevent tuberculous meningitis? Arch Dis Childhood. 1996; 74:144-7.

18. Syed SSM, Butt Z K, Mohammad S, Rafique M. Nutritional Assessment of children under $\mathbf{6 0}$ months in Sialkot. J Pak Med Stud. 2011; 1(1-3):7-12.

19. Syed SS. Prevalence of Iron Deficiency anaemia in school and laboured children of 10-15 years of age. SOUVENIR, 15th National Quetta: Pediatric Conference; 2011. P. 41-42.

20. Rubin SA. Tuberculosis: Captain of all these men of death. RadiolClin North Am. 1995; 33:619-39.

21. Macallan DC. Malnutrition in tuberculosis. Diagn Microbiol Infect Dis. 1999; 34:153-7.

22. Global programme for vaccines and immunizationExpanded programme on immunization. 1996. Immunization Policy. WHO/Extended Programme on Immunization/Geneva/95.03, Rev. 1. Geneva: World Health Organization; 1996.
23. Ponnighaus JM, Msosa E, Gruer PJ, Liomba NG, Fine PE, Sterne JA, Wilson RJ, Bliss L, Jenkins PA, Lucas SB. Efficacy of BCG vaccine against leprosy and tuberculosis in northern Malawi. The Lancet. 1992 Mar 14;339(8794):636-9.

24. Behr MA, Wilson MA, Gill WP, Salamon H, Schoolnik GK, Rane S, Small PM. Comparative genomics of BCG vaccines by whole-genome DNA microarray. Science. 1999 May 28;284(5419):1520-3.

25. Sterne JA, Rodrigues LC, Guedes IN. Does the efficacy of BCG decline with time since vaccination? Int J Tuberc Lung Dis. [In Press]

26. Colditz A, Brewer TF, Berkley CS. Efficacy of BCG vaccine in the prevention of tuberculosis. JAMA.1994; 271:698-702.

27. Myint TT, Win H, Aye HH, Kyaw-Mint TO. Case-control study on evaluation of BCG vaccination of newborn in Rangoon, Burma. Ann Trop Paediatr. 1987; 7:15966.

28. Filho VW, Castilho EA, Rodrigues LC, Huttly SRA. Effectiveness of BCG vaccination against tuberculousmeningitis: A case-control study in Sao Paulo, Brazil. Bull World Health Organ. 1990; 68:69-74.

29. Sharma RS, Srivastava DK, Singh AA. Epidemiological evaluation of BCG vaccine efficacy in Delhi, 1989. J Commun Disord. 1989; 21:200-6.

30. Report of a WHO study group. BCG vaccination policies. World Health Organ Tech Rep Ser. 1980; 652:5-17.

31. Udani PM, Parekh UC, Dasfur DK. Some neurological syndromes in CNS tuberculosis. Neurol India. 1972; Suppl:63-9.

\begin{tabular}{|c|l|l|}
\hline \multicolumn{3}{|c|}{ AUTHORSHIP AND CONTRIBUTION DECLARATION } \\
\hline Sr. \# & \multicolumn{1}{|c|}{ Author-s Full Name } & \multicolumn{1}{c|}{ Contribution to the paper } \\
\hline 1 & Shamaeel & $\begin{array}{l}\text { Collected and interpreted data } \\
\text { from pediatric department. } \\
\text { Contribution for conception } \\
\text { and design, Analysis and } \\
\text { interpretation of data. }\end{array}$ \\
\hline 3 & Farzana Shaikh & $\begin{array}{l}\text { Ghulam Shabbir Laghari } \\
\text { Collected and interpreted the } \\
\text { data. } \\
\text { Final reversion of data. }\end{array}$ \\
\hline 4 & Yasmeen Memon & Auth \\
\hline
\end{tabular}

